\title{
Relationships between The self-worth and Beliefs in a just world with life (1) satisfaction of elderly People \\ CrossMark \\ *Yamini $\mathrm{M}^{1}$, Sadidi $\mathrm{M}^{2}$
}

1- Ph.D, Department of Psychology, Kheradgerayan Motahar University, Mashad, Iran (Corresponding Author) Email: Yamini1342@gmail.com

2- Msc, Department of Counseling, Faculty of psychology and Education, Allameh Tabatabaee University, Tehran, Iran.

\section{Abstract}

Introduction: Due to the growth of aging population in the country, this group faces increasing problems. Considering the importance of improving the health of the elderly and the need to pay attention to the components of health promotion, especially mental health, There will be expected steps to be taken in this regard. One of the things that helps mental health in the elderly is having a life satisfaction. The aim of this study was to investigate the relationship between between the selfworth and Beliefs in a just world with life satisfaction of elderly People in the Esfarayen city, Iran.

Method: The research was a descriptive-correlational study. The statistical population of the study was all retired elderly people of the government offices in Esfarayen city in the year 20172018 who were 55 to 65 years old. 330 students were selected by available sampling. The research instruments were Just World Scale, Contingencies of Self-Worth Scale and life Satisfaction index. Data were analyzed using Pearson correlation coefficient and multiple regression.

Results: The results of correlation coefficient showed that the correlation between self-worth and life satisfaction was 0.381 . Also the correlation between belief in the fair world with life satisfaction was 0.413 . All the correlations were significant at the level of 0.001 . Also, multiple regression analysis showed that predictor variables explained $56 \%$ of variance in Satisfaction with Life.

Conclusion: results indicate that self-worth and belief in the fair world have significant and positive correlation with satisfaction with life.Thus, it seems that developing a sense of self-worth and having a belief in the fair world can make life satisfaction.

Keywords: contingencies of self- worth, belief in a just world, life satisfaction, elderly.

\begin{tabular}{|l|l|}
\hline \multicolumn{3}{|c|}{ Access this article online } \\
\hline
\end{tabular}




\section{رابطه واسطه هاى خودارزشمندى و نتاه به دنياى عادلانه بار ضايت از زندكى سالمندان}

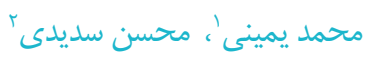

1- استاديار كروه روانشناسى، موسسه آموزش عالى خردكر ايان مطهر، مشهل، ايران (نويسنده مسئول) يست الكترونيكى: yaminilmer@gmail.com r- كارشناس ارشد مشاوره مدرسه، دانشخاه علامه طباطبايى، تهران، ايران.

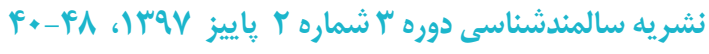

مقدمه: با توجه به افزايش جمعيت سالمندى در كشور، اين قشر با مشكلات فزاينده اى مواجه هستند . توجه به اهميت ارتقاء سلامت سالمندان و ضرورت توجه به مولفه هاى ارتقاء سلامت خصوصا سلامت روانى ايجاب مى كند كه تا حد ممكن در اين زمينه كام هايى بر داشته شود. يكى از جند إنبه هايى كه به سلامت روان سالمندان كمى مى كند، داشتن رضايت از زندكى است. اين مطالعه با هدف بررسى رابطه خودارزشمندى و نكاه به به دنياى عادلانه با رضايت از زندكى سالمندان انجام شده است.

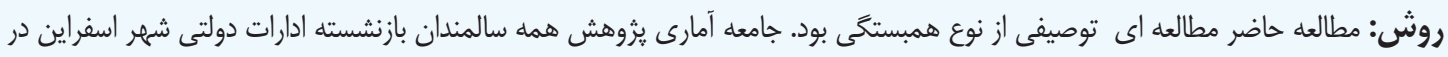

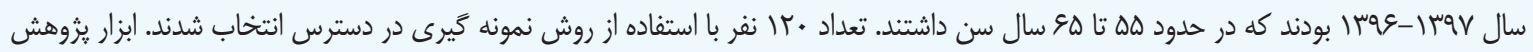

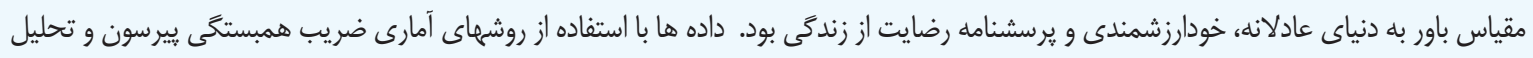
ركر سيون קندكانه تحليل شدند.

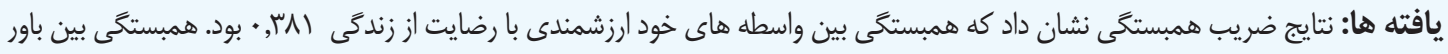

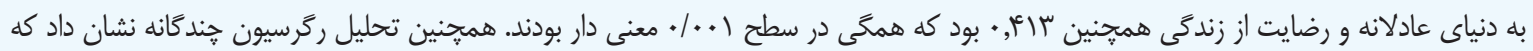

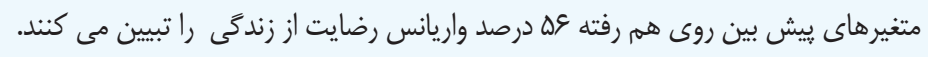

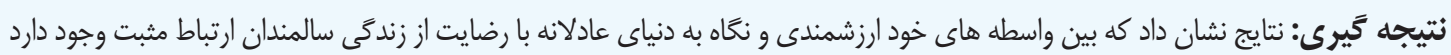

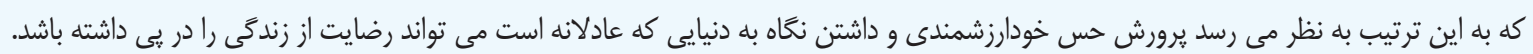

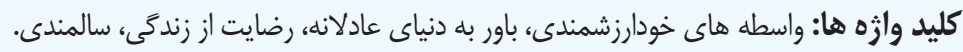

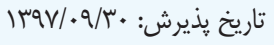
تاريخ دريافت: |• 
و عزت نفس به سمت خود نشانه رفته به ارزيابى فرد از خود اشاره

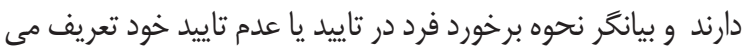
شوند (•). البته كروكر و ولف (^) به نوعى خود ارزشمندى و عزت

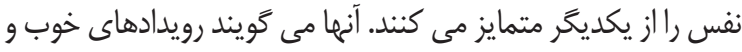
بد به واسطه خود ارزشخَارى هاى فردى، باعث احساس هاى موقتى مئى در انسان مى شوند كه در عزت نفس كم و يا زياد فرد آشكار مى شوند و اين نوسان در احساس هاى موقتى، بالا و يايين رفتن عزت نفس را سبب مى شوند كه ييامدهاى انكيزشى متفاوتى را به وجود مى آورد (به عبارتى سيستم ارزش كذارى مهمتر از عزت نفس في فرد مى شود). در حقيقت به قول سيزينسكى و همكاران آنحه كه افراد را به سمت رفتارهايشان به ييش مى برد و انخَيزه مى دهد باور آنها

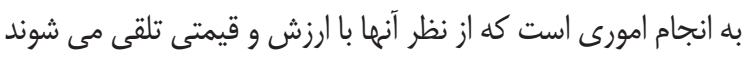
(1). از نظر كروكر و ولف (1) نيز واسطه هايى كه فرد به خاطر آنها خود را با ارزش تلقى مى كنند از خود عزت نفس اهميت بيشترى دارد. آنها معتقدند عزت نفس با احساس هاى خوب و بد همبستخى

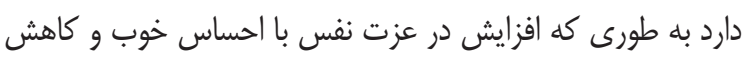

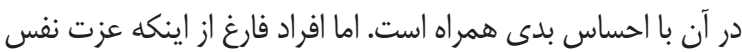
يايين يا بالايى داشته باشد، اخر موفقيت را در حيطه هايى تجربه

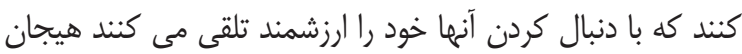
مثبت و در غير اين صورت هيجان منفى را تجربه خواهند كردو اين

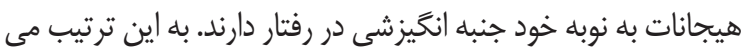
توان كفت كه اين وابسته ها كه افراد به واسطه آنها خود را ارزشمند و يا بى ارزش تلقى مى كنند، مهم و تنظيه كننده رفتار هستند نه عزت نفس (^). در سالمندان نيز جنين هيزى مى مي تواند صادق باشد.

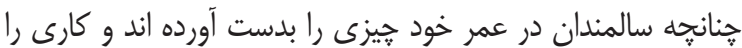
انجام داده اند كه براى آنها با ارزش بوده است بايد عزت نفس بالايى

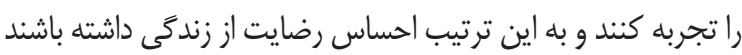
و برعكس. كروكر و كروكر و ولف بر اساس مدل نظرى "واسطه تربه هاى خودارزشمندى "سعى در تبيين קَخونكى شكل گيرى عزت نفس دارند و بنيانى مهمه براى بررسى شكل گيرى عزت نفس را

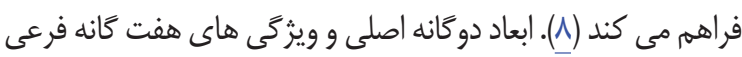
خودارزشمندى بر اساس مدل نظرى كروكر و ولف (^) عبارتند از: بعد درونى خودارزشمندى كه شامل : ميزان قيمت و بمهاء خويشتن با توجه به ميزان وجود حمايت از سوى خانواده؛ ميزان ارزش و توجه خويشتن نسبت به عشق خدايى و ميزان اهميت و بهاء خويشتن نسبت به حوزه تقوى و يرهيز كارى. بعد بيرونى خودارزشمندى: ميزان ارزش و قيمت خويشتن نسبت به شايستخى هاى علمى و آموزشى؛ ميزان اهميت و بهاء
مقلهمه

جمعيت سالمندان در جهان به سرعت رو به افزايش است. كاهش زاد و ولد و افزايش اميد به زندگى موجب شده است كهن به جمعيت سالمندان بسيار سريع تر از جمعيت كلى افزايش يابد و اين موضوع مشكلات بسيارى را براى اجتماع به بار مى آورد. طبق گَزارش مركز

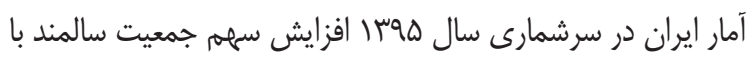

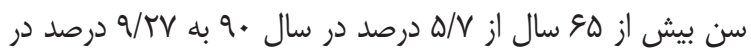
سال ه9 رسيده است (1). سالمندى جمعيت و بار بالاى بيماريها در

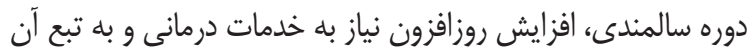
افزايش هزينه هاى نظام سلامت را در يى دارد كه ايجاب مى كند

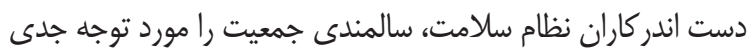
قرار داده و براى مواجهه با اين واقعيت اجتناب نايذير تمهيدات لازم را فراهم نمايند (ז). يكى از خالش هاى مهمى كه فرد در دوران حساس سالمندى با آن مواجه مى شود حفظ و ارتقاى بهداشت روانى است. يكى از شاخص هاى سلامت روانى كه ناشى از ارزيابى شناختى و عاطفى فرد از زندگى مى باشد رضايت از زندگى است كه مورد توجه بسيارى از متخصصان مختلف در حوزه سالمندى قرار گرفته است. رضايت از زندگى به عنوان قضاوت شخصى از سعادت و بهروزى و

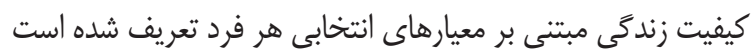
(1). در واقع رضايت از زندگى مفهوم كلى و ناشى از نحوهُ ادراك (شناختى و عاطفى) شخص از كل زندگى است (أ)؛؛ به همين دليل،

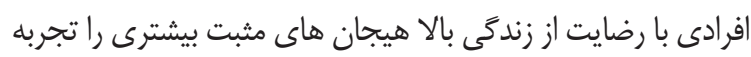

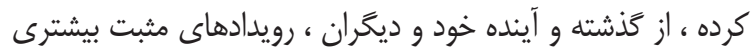

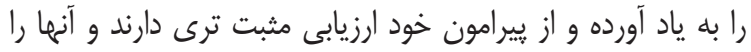

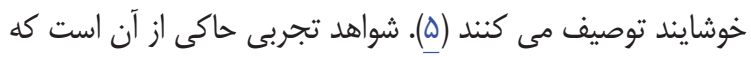

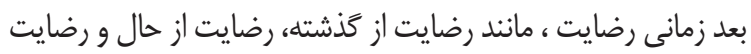

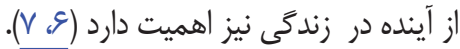
رضايت از زندگى مى تواند تحت تاثير برداشت ها و باورهاى

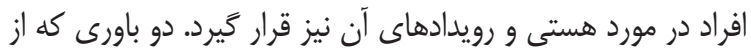
نظر اين مقاله در رضايت از زندگى سالمندان مى توانند تاثير داشته باشند، يكى باور به دنبال كردن امور ارزشمند در طول زندگى از

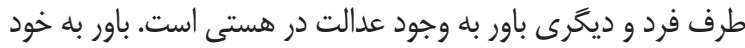

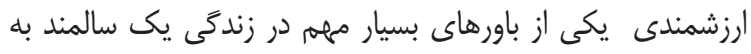

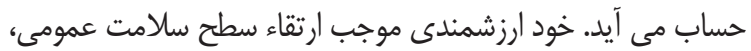
خودتنظيمى، منبع انخيزش، كاهش افسردگى و اصلاح رفتاراجتماعى،

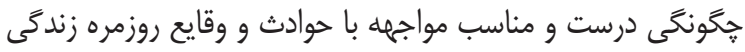
بوده كه در سطوح مختلف زندگى فردى، خانوادگى، آموزشى و

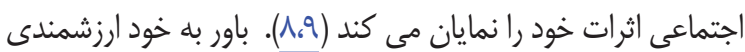


و خود ارزشمندى با رضايت از زندگى در بازنشستخان ادارات دولتى

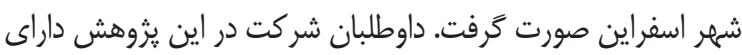
سن هD تا ه 9 سال و همخى مرد و داراى سطح تحصيلات ديبلم

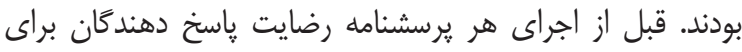

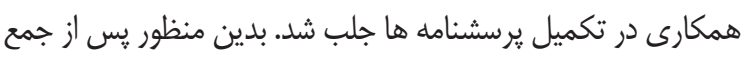
آورى داده هاى خام از طريق يرسشنامه نتايج تحليل آمارى ارائه

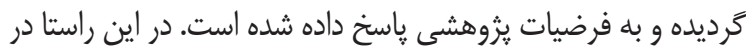
ابتدا تحليل توصيفى داده ها انجام شده و در ادامه دادهاى استنباطى برى ارائه و مورد بررسى قرار كَرفته است. ابزارها

يرسشنامه باورهاى دنياى عادلانه (براى خود و ديگران ):

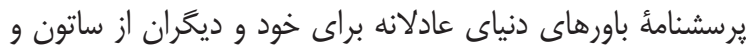

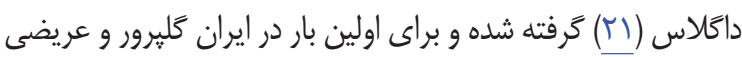

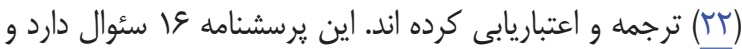
نمره كذارى آن بر اساس طيف ليكرت است. به اين ترتيب كه به به

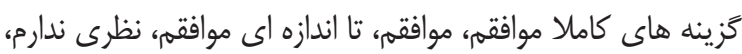
تا اندازه اى مخالفم، مخالفم و كاملا مخالفم به ترتيب نمره هاى ا تا Vتعلق مى كَيرد. اين مولفان يرسشنامه را يايايى سنجى كرده

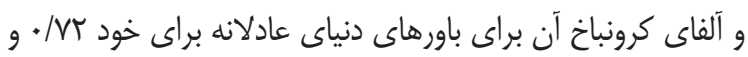

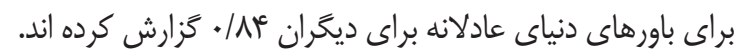

\section{مقياس واسطه هاى خود- ارزشمندى (CSWS)}

مقياس واسطه هاى خود- ارزشمندى را كروكر و همكاران

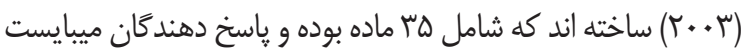
در طيف ليكرت V درجه اى ( إ شديداً مخالف، V= شديداً موافق) به عبارات ياسخ دهند. زير مقياسهاى اين مقياس عبارتند از: بُعد درونى خودارزشمندى (حمايت و عشق خانوادگى، عشق به خدا، تقوا

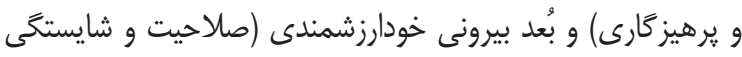
علمى، رقابت و سبقت جويى، فيزيكى و ظاهرى، تأييد ديكران). نسخه ى انحَليسى اين مقياس بر طبق كزارش كراكر و همكاران

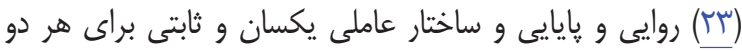
جنس دارد. مقياس خودارزشمندى داراى روايى و پايايى بسيار مطلوبى بوده و متناسب با فرهنخ ايران قابل استفاده ميباشد. سبزه آراى لنغرودى و همكاران (بآ) در يزوهشى نشان دادند شش عامل

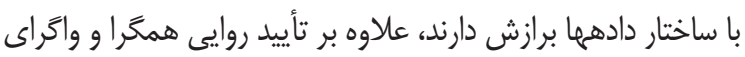
مقياس، ضرايب آلفاى كرونباخ نيز همسانى درونى مناسب مقياسهاى دارئ

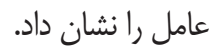
يرسشنامه رضايت از زندگى LSI-Z: نسخه اصلى يرسشنامه

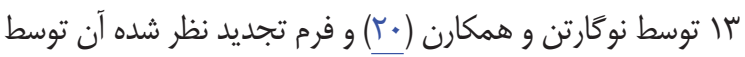

خويشتن نسبت به حوزه رقابت و سبقت جويى؛ ميزان ارزش خويشتن

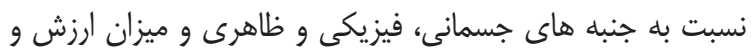
قيمت خويشتن در حوزه هاى مورد موافقت ديخران بودن همان كونه

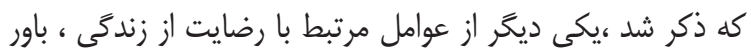

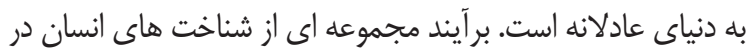

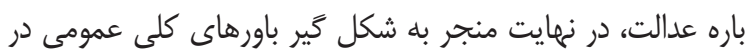
باره عادلانه و يا ناعادلانه بودن شر ايط دنيا مى شود كه روى رضايت از ز زندگى فرد تاثير مى كذارد.

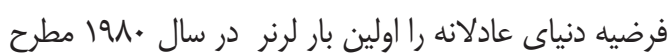
كرد (T/أl|). بر اساس اين فرضيه بيان مى شود كه انسانها در دنياى كنونى برانخيخته مى شوند تا اين عقيده را يبيدا كنند كه در

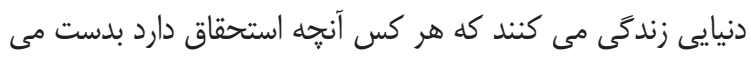

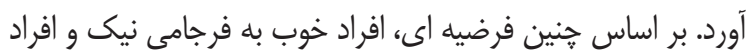
بد به فرجام بدى مى رسند (ه)). باور به دنياى عادلانه موجب كاهش اله حالت هاى هيجانى منفى و تجربه هاى هيجانى مثبت بيشتر شده

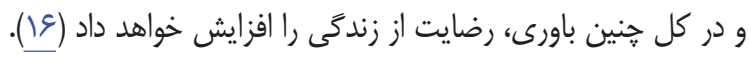
دالبرت و ميس بين باور به عادلانه بودن دنيا و جنبه هاى كَوناكون

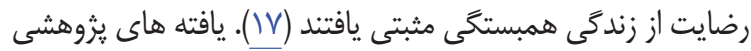
كوريا، توسكانو و ليما نشان داد كه ميان باور به عادلانه بودن دنيا و رضايت از زندگى، رابطه معنى دارى وجود دارد (1) (1). جانگ، يو، لو ، يو و زو در يزوهش خود دريافتند كه بين باور به دنياى عادلانه، سلامت روان ، خوش بينى و بهزيستى ارتباط وجود دارد و افزايش بهزيستى روانى باور به دنياى عادلانه، سلامت روان و خوش بينى را تحت تاثير قرار مى دهد (19). به طور مشابه رايتر، بنسون و اشنايدر نبز بى برده اند كه باورهاى دنياى عادلانه رابطأ منفى با عاطفة منفى و افسردگى دارند

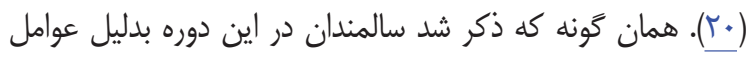

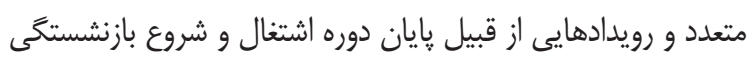
با نخرانى هايى مانند تنهايى، طردشدگى و احساس به بايان خط رسيدن، يوجى، بى هدفى، اضطراب، افسردگى، ترس از طرد شدن

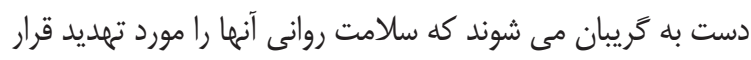
مى دهد. مقاله حاضر همان كَونه كه ذكر شد در يَى آن است تان نشان دهد كه وجود منابعى كه فرد به واسطه ى آنها براى خود ارزش قائل بيشترى قائل شود (خود-رزشمندى)؛ و باور به دنياى عادلانه مى تواند رضايت از زندكى را در سالمندان بيش بينى نمايد.

\section{ورش مطالعها}

يزوهش حاضر به منظور بررسى رابطه باور به دنياى عادلانه 
دنياى عادلانه براى خود داراى ميانكَين نمره (•.9.5) و انحراف

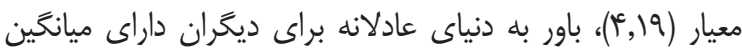

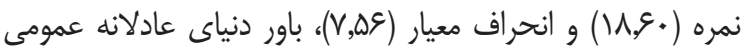

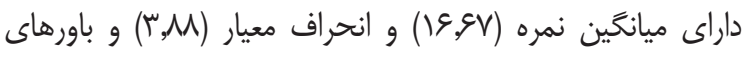

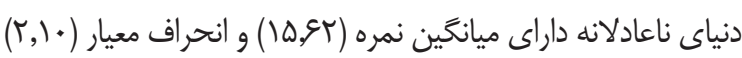

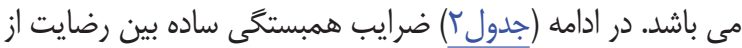
زندگى، خود ارزشمندى و دنياى عادلانه براى خود، ديخران، دنياى عادلانه عمومى و و دنياى ناعادلانه را نشان مى دهد.
وود، وايلى و شيفور (هاr) تهيه شده است كه زهرا تقربى و همكاران

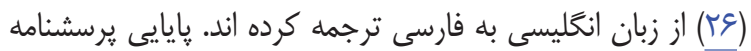
برابر با V9/ • بدست أمده است نمره بالاتر در اين آزمون بيانكَر بالاتر بودن سطح رضايت از زندگى است.

بافْته ها همان طور كه در (جدول () مشاهده مى شود رضايت از زندگى

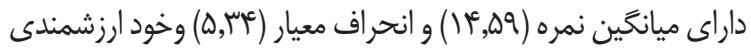

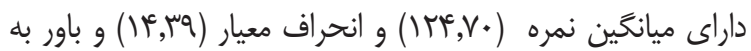

جدول (ا: اطلاعات توصيفى نمونه مورد بررسى در متغيرهاى مورد بررسى

\begin{tabular}{|c|c|c|c|c|c|c|}
\hline حجم نمونه & انحراف استاندارد & ميانخين & بيشترين & كمترين & & \\
\hline ir. & $\Delta, \mu r$ & $1 f, 90$ & tr & 9 & رضايت از زندگى & رضايت از زندگى \\
\hline$\pi$ & 9.99 & $r$ r,qF & ז & 19 & حمايت خانواده & \\
\hline$\pi$ & r,r. & $r Q, r \Lambda$ & rq & rI & رقابت & خود ارزشمندى \\
\hline$\pi$ & 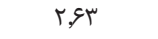 & $r \mid, g r$ & re & $M$ & ظاهر & \\
\hline$\pi$ & $\Delta, \xi \varphi$ & $r \Delta, 9 \Delta$ & r. & $M$ & عشق به خدا & \\
\hline$\pi r$. & $\mathrm{V}, \Delta \mathrm{H}$ & 10,10 & ta & $\checkmark$ & شايستخى تحصيلى & \\
\hline ir. & $\varepsilon, r_{1}$ & rr.g. & rt & IV & يرهيز & \\
\hline$\pi$ & $1, g r$ & $11, \vee \Delta$ & זr & 1. & تاييد از جانب ديخران & \\
\hline$\pi$ & 14, rq & ITE,V. & 148 & $1 \cdot V$ & نمره كل & \\
\hline ir. & 1,19 & re.g. & r & MI & باور عادلانه براى خود & باور به دنياى عادلانه \\
\hline ir. & $\checkmark, \Delta S$ & $1 \wedge, \xi$ & rq & 11 & باور عادلانه براى ديخران & \\
\hline$\pi$. & $r, \Lambda$ & $19.9 \mathrm{~V}$ & זr & r & باور دنياى عادلانه عمومى & \\
\hline$\pi$. & $r, 1$. & $10, g r$ & M & 11 & باور دنياى ناعادلانه & \\
\hline
\end{tabular}

جدول r: همبستخى باور به دنياى عادلانه و خود ارزشمندى با رضايت از زندگى در سالمندان

\begin{tabular}{|c|c|c|c|c|c|c|c|c|c|c|c|c|c|}
\hline rו & Ir & 11 & 1. & 9 & $\wedge$ & $v$ & 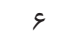 & $\Delta$ & f & r & $r$ & 1 & \\
\hline 1 & $\begin{array}{c}1 \\
* *-T V\end{array}$ & $\begin{array}{c}1 \\
\cdots r \\
* *+, 1\end{array}$ & $\begin{array}{c}1 \\
* 91 \\
-. .99 \\
* * .9 \mu\end{array}$ & 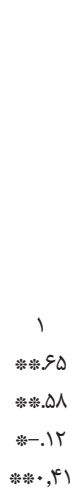 & $\begin{array}{c}1 \\
* .11 \\
* .1 \gamma \\
* .11 \\
*-19 \\
* * .14 \text { 人 }\end{array}$ & $\begin{array}{c}1 \\
* \% .9 q \\
* .11 \\
.9 \\
* .5 . \\
.1 . \\
* \%+, q V\end{array}$ & $\begin{array}{c}1 \\
* .19 \\
* \% . r 9 \\
* .19 \\
.9 \\
.9 \\
*-.5 \Delta \\
* \%+, r V\end{array}$ & 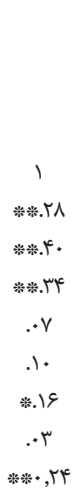 & 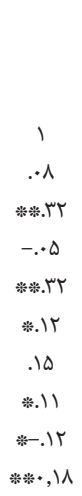 & 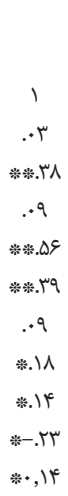 & 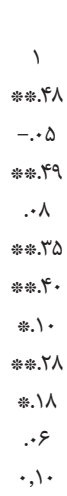 & 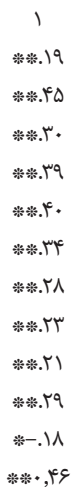 & 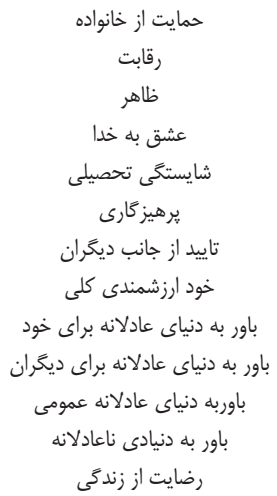 \\
\hline
\end{tabular}

عمومى (P>, (P> و باورهاى دنياى ناعادلانه از مولفه هاى باور به دنياى عادلانه با رضايت از زندگى رابطه وجود دارد. در ادامه جهت

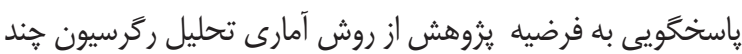
متغيره استفاده شد كه نتايج آن در جدول زير ارائه شده است. همان طور كه مشاهده مى شود تعداد مدل هاى وارد شده به ركر سيون سه انه مدل باور به دنياى عادلانه براى ديخران، باور به دنياى عادلانه براى خود و خود ارزشمندى مى باشند.
همانگگُنه كه داده هاى ارائه شده در (جدول r) نشان مى دهد با توجه به نتايج بدست آمده مى توان نتيجه كَرفت كه بين حمايت

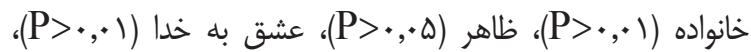
شايستى تحصيلى (1)

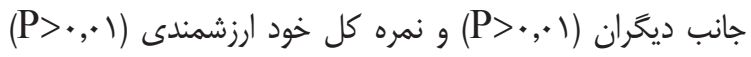

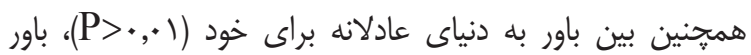
به دنياى عادلانه براى ديغران (1), (P>)، باور دنياى عادلانه 
جدول سا: مربوط به نتايج تحليل ركَ سيون گام به كام رضايت از زندگى بر اساس خود ارزشمندى و باور به دنياى عادلانه

\begin{tabular}{|c|c|c|c|c|c|c|}
\hline Rr & $\mathrm{F}$ & Sig. & $\mathrm{t}$ & $\beta$ & B & متغيرها \\
\hline - (199 & $\wedge \backslash, \wedge\rceil$. & $\cdot, \cdot \cdot 1$ & $0, \wedge 9 \vee$ & إسو. & $\cdot, \mathrm{V} F \Lambda$ & باور به دنياى عادلانه براى ديگران \\
\hline$\cdot$, rqu & VQ,Trd & $\cdot, \cdot \cdot 1$ & TEME & $\cdot, r M$ & 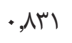 & باور به دنياى عادلانه براى خود \\
\hline س بS, & $\mid \cdot f, k) \mid$ & $\cdot, \cdot \cdot 1$ & r,r. & qqu & $\cdot, \Delta F$. & خود ارزشمندى \\
\hline
\end{tabular}

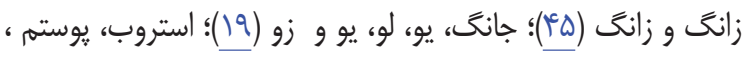

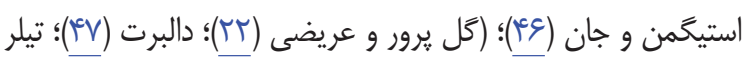

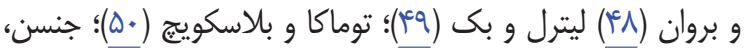

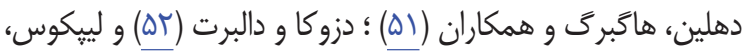
دالبرت و زيخلر (سبه) اشاره كرد. بلدون شك يكى از فاكتورهاى اساسى و مهم تاثيرگذار بر وضعيت بهراشت روان در دوره سالمندى رضايت از زندگى است. به به به نظرمى رسد عوامل اقتصادى، اجتماعى و فرهنگَى، وضعيت رضايت

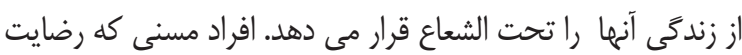
از زندگى بالاترى دارند، انجام رفتارهاى حفاظتى و توسعه سلامتى را براحتى يذيرا مى باشند. از آنجا كه رضايت از زندگى به ارزيابى كلى

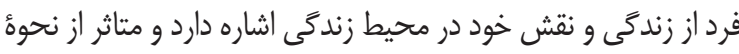

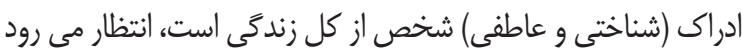
اين متغير با نخاه به دنيا و محيط اطراف خود و برداشت فرد از ارزش خود ارتباط داشته باشد.

اهميت ابعاد جسمى، اجتماعى و روانى و وابستخى آنها به به به يكديخر در دوران هاى مختلف حيات انسانى بر كسى يوشيده نيست. اما، اين ابعاد و ارتباط آنها با يكديخر در دوران سالمندى از اهميت ويزه اى برخوردار مى شوند. ديدكاه سالمندان نسبت به وجود عدالت مى تواند به اشكال مختلف، نحوه ى واكنش آنها را نسبت به رخدي رخدادها

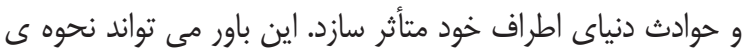
رفتار و برنامهريزى براى آينده (كه جندان هم طولانى به نظر نمى رسد)، شاخص هاى سلامت روانى نظير عاطفه ى مثبت و منفى، افسردگى، كيفيت زندگى و رضايت از زندگى آنها را تحت تاثير قرار

از طرفى عزت نفس به عنوان يكى از قطعى ترين عوامل در

سلامت روانى سالمندان، مى تواند اثرات جبران نايذيرى در جريان فكرى، احساسات، تمايلات، ارزش ها و هدف هاى آنها بر جاى بحَارد. بر اساس يافته هاى تحقيق حاضر انتظار مى رود سالمندى كه ازمنابع احساس خود ارزشمندى بالاترى برخوردار باشد و نحاه عادلانه نسبت به دنيا داشته باشد، بتواند با تهلديدها و وقايع اضطراب

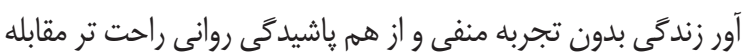
نمايد و از زندگى خود رضايت بيشترى داشته باشد.
همان طور كه در (جدولب) مشاهده مى شود، در مدل نخست باور به دنياى عادلانه براى ديخران وارد معادله شد كه اين متغير قادر به يِيش بينى رضايت از زندگى به ميزان • أ درصد در نمونه حاضر بود. در مدل دوم كه باور به دنياى عادلانه براى خود وارد معادله شد

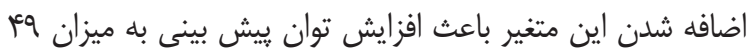
درصد شد و در مدل سوم اضافه شدن متغير خود ارزشمندى باعث اضافه شدن توان يِيش بينى به ميزان وه درصد در نمونه حاضر شد. مطابق نتايج ارايه شده در جدول فوق مقدار ضرايب بتا براى باور به به به بـان

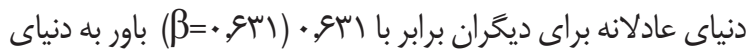

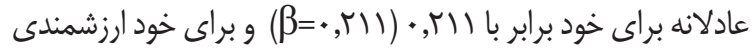

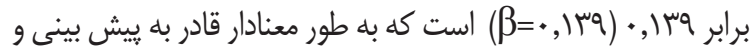
تبيين رضايت از زندگى در نمونه حاضر مى باشد.

هدف يزوهش حاضر بررسى رابطه واسطه هاى خودارزشمندى و نخاه عادلانه به دنيا با رضايت از زندگى در سالمندان بود. براى اين منظور با تحليل ماتريس همبستخى و ركرسيون گَام به كَام فرضيه هاى يثوهش آزمون شدند. همان گَونه كه نتايج حاضل از يزوهش نشان دادن، ضرايب همبستخى برآورد شده بين هر دو متغير واسطه

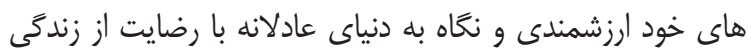
مثبت و معنادار به دست آمد. تحقيقات متعددى در اين زمينه به نقش برداشت فرد از خود و محيط در رضايت از زندگى اشاره داشته اند. تحقيقات همسو با يافته هاى اين تحقيق عبارتند از: فاركوهار (YV)؛ هيلرا و همكاران (r) (r)؛

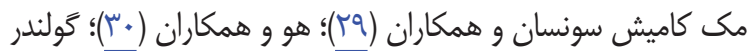

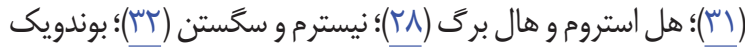

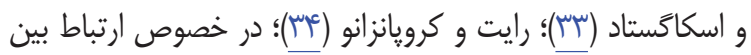
خود ارزشمندى و رضايت از زندگى به تحقيقات بلاسكوويج و توماكا

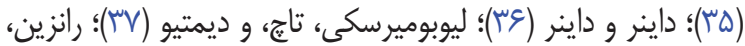
كيويس، لازكس (^ץ). در خصوص ارتباط بين نخاه به دنياى عادلانه و رضايت از زندگى مى توان به تحقيقات انجم شعاع (qَr)؛ خسروى يور و ناهيد يور (+1)؛ دالبرت و ميس (1) (†)؛ كوريا، توسكانو و ليما

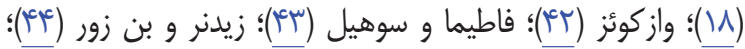


بر بازسازى و درك دوره زندگى افراد تاثير مى گذارد، تعاملات اجتماعى را جهت دهى مى كند، به افراد در رويارويى با خطرها و مشكلات روزمره يارى مى رساند و قربانيان بى عدالتى را يارى مى بـى دهد و تحمل آنها را در مقابل بى عدالتى ها بيشتر مى كند. همجنين عقيده به دنياى عادلانه يك منبع شخصى نيرومند در فرآيند مقابله و سازش افر اد با دنياى اطراف به شيوه هاى متفاوت تاثير مى كذارد. در پايان يِيشنهاد مى شود در تحقيقات آينده رابطه خود ارزشمندى درونى و بيرونى با رضايت از زندگى در سالمندان مورد توجه بيشتر قرار گيرد.

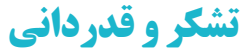

از همكارى تمام عزيزان سالمندى كه در اين يثوهش

$$
\text { همكارى نمودند، تشكر و قدردانى مى شود. }
$$

\section{References}

1. Ahmadi and Beheshti QP. Study of demographic and welfare characteristics of the elderly in Iran. Population Quarterly. 2008; 61:38-19.

2. Imani D, Azizi Zein al-Hajjlo,. Image of Health. 2016; 54 (6):6.

3. Keyes CLM, Shmotkin, D., \& Ryff, C.D. Optimizing well-being: The empirical encounter of two traditions. Journal of Personality and Social Psychology. 2002; 82 (6):1007-22.

4. E BAG. Changes in functional ability in three samples of elderly and very elderly people. Age and Ageing. 1997; 26: 107-14.

5. Thimm JC. Personality and early maladaptive schemas: A five-factor model perspective. Journal of Behavior Therapy and Experimental Psychiatry. 2010;, 41, 373-380.:, 373-80.

6. Lucas RE DE, Suh E. Discriminant validity of well- being measures. Journal of personality and Social Psychology. 1996; 71: 616-28.

7. Pavot W DE, Suh E. The temporal satisfaction with life scale. Journal of Personality Assessment. 1998; 70:340- 54.

8. Crocker J, \& Wolfe, C. T. Contingencies of selfworth. Psychological Review. 2001; 108: $593-$ 623.

9. Crocker J, Sommers, S. R., \& Luhtanen, R. K. Hopes dashed and dreams fulfilled: Contingencies of self-worth and admissions to graduate school. Personality and Social Psychology Bulletin.

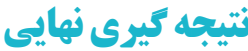

هر קند عزت نفس هر انسانى با رفتارهاى او در ارتباط است

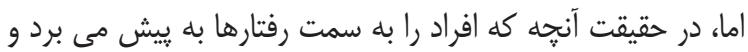
انخَيزه مى دهد منابع ارزش كذارى براى خود هستند. هر خه يايه و بنيادهاى عزت نفس كه همان منابع ارزش كذارى فرد براى خود مى

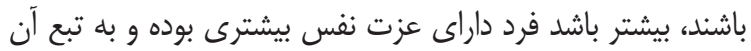

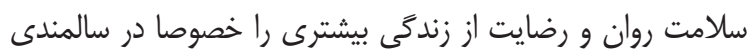

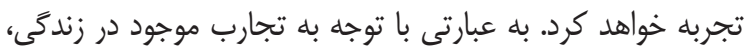
هر قدر مردم واسطه هاى بيشترى براى ارزش كذارى و حفظ منزلت

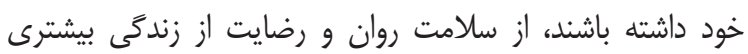

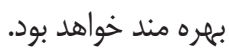

شواهد نشان مى دهد كه علاوه بر خود ارزشمندى، باور به دنياى عادلانه نيز نقش كاربردى و مثبت دارد. باور به دنياى عادلانه 2002; 28: 1275-86.

10. Rosenberg M. Society and the Adolescent Selfimage: Princeton University Press; 1965.

11. Pyszczynski T SS, Greenberg J, Arndt J, Schimel J. Converging toward an integrated theory of self-esteem: Reply to Crocker and Nuer (2004), Ryan and Deci (2004), and Leary (2004). Psychological Bulletin.130: 483-8.

12. Lerner MJ. The Belief in a Just World: A Fundamental Delusion. New York: Plenum.

13. Furnham A, \& Procter, E. Belief in a just world: Review and critique of the individual difference literature. British Journal of Social Psychology. 1989; 28:365-84.

14. Lerner MJ, \& Miller, D. T. Just world research and the attribution process: Looking back and ahead. Psychological Bulletin. 1978; 85:1030 51.

15. McParland JL, Knussen, C. Just world beliefs moderate the relationship of pain intensity and disability with psychological distress in chronic pain support group members. European journal of Pain. 2010;14 (1):71-6.

16. Rahpardaz F, Shirazi, Mahmoud. The role of Belief in a Just World in predicting student'slife satisfaction. Journal of Educational Psychology. $2015 ; 24$.

17. Dalbert CaM, J. Belief in a just world as a persona resource in school', in M. Ross and D. T. Miller (eds), The Justice Motive in Everyday 
Life, Cambridge: Cambridge University Press.

18. Correia I, Toscano Batista, M., \& Lima, ML. Does the belief in a just world bring happiness? Causal relationships among belief in a just world, life satisfaction and mood. Australian Journal of Psychology. 2009; 61 (4): 220-7.

19. Jiang F, Yue,X., Lu,S., Zhu, F. Bottom of Form Belief in a just world Gratitude optimism Subjective well-being Depression. Social Indicators Research. 2015;126 (1): 411-23.

20. Neugarten BL, R. J. Havighurst and S. S. Tobin. The measurement of life satisfaction. Journal of Gerontology. 1961 (16):134-43.

21. Sutton RM, \& Douglas, K. M. Justice for all, or just for me? More evidence of the importance of the self-other distinction in just-world beliefs. Personality and Individual Differences. 2005; 39:637-45.

22. Golparvar M AH. Validation of the questionnaire of belief in a just world for themselves and others. Journal of Humanities University of Isfahan. 2007; 25 (4):212-193.

23. Crocker J, Luhtanen, R. K., Cooper, M. L., \& Bouvrette, A. Contingencies of self-worth in college students: Theory and measurement. Journal of Personality and Social Psychology. 2003; 85: 894-908.

24. Milad SabzehAra YLF, Mehdi Reza Sarafraz \& Mostafa Mohammadi (2014) An Investigation of the Associations Between Contingent Self-Worth and Aspirations Among Iranian University Students. The Journal of Social Psychology. 154 (1):59-73.

25. Wood V, Wylie, M. L., Sheafor, B. Analysis of a short self-report measure of life satisfaction: Correlation with rater judgements. Gerontology. 1969; 24:470-4.

26. Tagharrobi.Zahra SK, Sooki. Zahra, Tagharrobi, Leila. Psychometric properties of Short Form Of Life SatisfactionQuestionnaire in students Of Kashan Nursing and Midwifery Faculty. Qom University of Medical Sciences Journal. 2012; 1:89-98.

27. Farquhar M. Definitions of quality of life: A taxonomy. Journal of Advanced Nursing. 1995; 22:502-8. .

28. Hillera $^{\circ}$ s P JA, Herlitz A \& Winblad B. Life satisfaction among the very old: a survey on a cognitively intact sample aged 90 years and above. International Journal Aging and Human Development 2001; 52: 71-90.

29. McCamish-Svensson C SG, Hagberg B, Svensson $\mathrm{T} \&$ Dehlin O. Social relationships and health as predictors of life satisfaction in advanced old age: results from a Swedish longitudinal study. International Journal Aging and Human Development.48:301-24.

30. Ho SC WJ, Lau J, Chan SG, Yuen YK, Chan YK $\&$ Chi I Life satisfaction and associated factors in older Hong Kong Chinese. Life satisfaction and associated factors in older Hong Kong Chinese. 1995; 43: 252-5.

31. Gueldner SH LS, Morris D, Penrod J, Bramlett M, Johnston L \& Schlotzhauer P A comparison of life satisfaction and mood in nursing home residents and community-dwelling elders. Archives of Psychiatric Nursing.15:232-40.

32. KA NmAS. Peace of mind as an important aspect of old people's health. Scandinavian Journal of Caring Sciences. 1990; 4: 55-62.

33. A BMS. The oldest old, ADL, social network, and loneliness. Western Journal of Nursing Research. 1998; 20: 325-43.

34. Wright TA, \& Cropanzano, R. Emotional exhaustion as a predictor of job performance and voluntary turnover. Journal of Applied Psychology. 1998; 83 (3): 486-93.

35. Blascovich J, \& Tomaka, J. Measures of personality and social psychological attitudes San Diego, CA: Academic Press.; 1991. San Diego, CA: Academic Press. p.

36. Diener E, Diener, M., \& Diener, C. Factors predicting the subjective well-being of nations. Journal of Personality and Social Psychology. 1995; 69: 851-64.

37. Lyubomirsky.S TCMDR. What are the differences between happiness and self-esteem? Social Indicators Research. 2006; 38: 363-404.

38. Rob Ranzijn JK, Mary Luszcz, and N. T. The Role of Self-Perceived Usefulness and Competence in the Self-Esteem of Elderly Adults: Confirmatory Factor Analyses of the Bachman Revision of Rosenberg's Self-Esteem Scale. Feather Journal of Gerontology:Feather Journal of Gerontology. 1998; 53B (2): P96-P104.

39. Anjom Sho'aa F. Master's dissertation: Kerman Shahid Bahonar University; 2013.

40. Khosravi Z, Nahidpour, Farzaneh. Evaluation 
of Life Satisfaction, Belief in a Just World and social support in Iranian and Indian students. Women's Sociology. 2013; 2: 13-3.

41. Dalbert CaM, J. Belief in a just world as a persona resource in school', in M. Ross and D. T. Miller (eds), The Justice Motive in Everyday Life: Cambridge: Cambridge University Press; 2002. 46. Dalbert, C. and Maes, J. (2002). Belief in a just world as a persona resource in school', in M. Ross and D. T. Miller (eds), The Justice Motive in Everyday Life, Cambridge: Cambridge University Press p.

42. Vazquez V. Just world belief, optimism, and wellbeing. Just world belief, optimism, and wellbeing. Available from:http://searchproquestcom/ docview/304922245. 2009.

43. Fatima I, Suhail, K. Belief in a just world and subjective wellbeing:mothers of normal and Down syndrome children. International journal of psychology. 2010; 45 (6),461- 468.

44. Zeidner M, Ben-Zur, H. Personal resources at the juncture of culture and life satisfaction. Personality and Individual Differences. 2013; 54 (2):187-91.

45. Zhang Z, Zhang,J. Belief in a just world mediates the relationship between institutional Trust and life satisfaction among the elderly in China. Personality and Individual Differences. 2015; 83:164-9.

46. Stroebe K, Postmes, T., Täuber, S., Stegeman, A., John, M.S. Belief in a Just What? Demystifying Just World Beliefs by Distinguishing Sources of Justice. PLoS ONE. 2015; 10 (3):1-30.

47. Dalbert c. the world is more just for me than generally. SocialJustice Research. 1999; 12: 7998.

48. Taylor SE, \& Brown, J. Q Illusion and wellbeing: A social psychological perspective on mental health. Psychological Bulletin. 1988; 103: $193-210$

49. Littrell J, \& Beck, E. . Predictors of depression in a sample of African- American homeless men: Identifying effective coping strategies given varying levels of daily stressors. Community Mental Health Journal. 2001; 37:15-29.

50. Tomaka J, \&Blascovich, J. Journal of Personality and Social Psychology. Journal of Personality and Social Psychology. 1994; 67:732-40.

51. Jensen OD, B. Hagberg, G. Samuelsson, T.
Seven. Insomnia in an 80-year-old population: Relationship to medical, psychological and social factors. Journal of Sleep factors 7: 183-9.

52. Dzuka J, \& Dalbert, C. Mental health and personality of Slovak unemployed adolescents: About the beliefs in a just world's impact. Journal of Applied Social Psychology. 2002; 4: 732-57

53. Lipkus 1M, Dalbert, C. and Siegler, I.C. The importance of distinguishing the belief in a just world for self versus for others: Implications for psychological well-being. Personality and Social Psychology Bulletin. 1996; 22: 666-77. 